\title{
Att överskrida ras: \\ En introduktion till begreppet transrasialitet speglad genom transrasiala erfarenheter och fantasier
}

Av Tobias HÜBINETTE

Denna artikel introducerar transrasialitetsbegreppet utifrain följande frågeställningar: $\ddot{A} v$ det möjligt att överskrida ras pà ett liknande sätt som det gair att överskrida kön? Hur ser den transrasiala erfarenbeten ut och hur skiljer den sig frain den transrasiala fantasin? Vem eller vilka är transrasiala, och är det samma sak att transrasialisera frain icke-vit till vit som frain vit till ickevit?

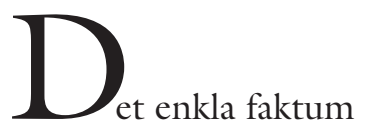

att ras tillsammans med kön är de två kategorier som de flesta människor oavsett ras och kön mer eller mindre omedelbart tar in och läser av hos andra människors kroppar vid ett första möte oavsett om de erkänner det för sig själva eller ej kan låta både trivialt och basalt att konstatera. Det finns inte heller något kön som inte har en ras och inte heller någon ras som inte har ett kön. Trots detta har kategorin ras inte blivit föremål för samma forskningsintresse som kategorin kön inom den samtida kritiska kultur- och samhällsvetenskapliga forskningen. På grund av en närhistoria av slavhandeln, Förintelsen, rastänkandet och kolonialismen med allt dess våld och alla dess folkmord brukar ras i de fall begreppet överhuvudtaget benämns pliktskyldigast sägas vara en social konstruktion, och den kontroversiella glosan sätts ofta inom citationstecken eller ersätts med begreppet etnicitet, och särskilt gäller detta i europeiska och nordiska sammanhang. Även om kön 
också betraktas som en social konstruktion av de flesta forskare så har forskningen om kategorin kön under senare decennier lett till mer teoretiskt avancerade och politiskt produktiva sätt att betrakta och behandla kön på i jämförelse med forskningen kring kategorin ras.

Den amerikanska feministiska filosofen och kritiska rasforskaren Linda Martín Alcoff (2005) har kritiserat det förenklade socialkonstruktionistiska sättet att se på ras, och menar att raskategorin förtjänar att operationaliseras och analyseras på ett liknande sätt som könskategorin mot bakgrund av hur utpräglat rasligt segregerade och strukturerade de senmoderna västerländska samhällena faktiskt är även i det postkoloniala tillståndet, och inklusive i Europa och Norden. Martín Alcoff talar om ras och kön som visuella och förkroppsligade identitetskategorier som med fördel kan förstås och förklaras som performativa subjektspositioner, och den australiensiska kritiska ras- och kulturstudierforskaren Sara Ahmed (2006) menar att ras och kön även bör analyseras på ett liknande sätt ur ett fenomenologiskt perspektiv för att förstå hur olika former av normativa och icke-normativa orienteringar både möter på motstånd och skapar förändring.

Det är denna övertygelse om att ras fortfarande är en kategori som bör beaktas och inte kan ersättas med eller täckas in i etnicitetsbegreppet, som utgör den teoretiska utgångspunkten i denna artikel som introducerar och undersöker begreppet transrasialitet speglad genom transrasiala erfarenheter och fantasier. ${ }^{1}$ Artikeln är inspirerad av kritiska ras- och vithetsstudier och poststrukturalistiska teorier om kön, sexualitet, förkroppsligande, materialisering och rasifiering (Butler 2004; Cheng 2001; Dyer 1997; Frankenberg 1993; Grosz 1994; Omi \& Winant 1986). Syftet med artikeln är inte att jämställa kön och ras, och ej heller att diskutera vilken kategori som kan tänkas överskugga den andra eller om olika former av överskridanden av kön och ras betyder samma sak. Samtidigt finns det både teoretiska och politiska poänger med att vara öppen för eventuella likheter och skillnader dem emellan, då ras och kön just båda är förkroppsligade och performativa kategorier som lyder under en liknande homogeniserande binaritet som både försvårar och även ofta straffar de som överskrider denna dikotomi.

Till skillnad från forskningen om transpersoner och könsöverskridande erfarenheter har transrasialitetsbegreppet och olika transrasiala praktiker ej tidigare varit föremål för någon mer omfattande forskning förutom som en teoretisk idé eller en politisk strategi i litteraturvetenskapliga och kulturstudiersammanhang i relation till frågor om hybriditet och passing, mixed race och adoption samt science fiction och cyborgar (se till exempel Eng 2010; Hawkins 2004; Myong Petersen 2009; Newlyn 2002). Återigen i motsats till forskningen om könsöverskridande praktiker där transpersoner själva alltmer har kommit att framträda som självständiga subjekt och som forskare från att tidigare i första hand ha varit informanter och objekt inom den medicinska transsexualismforskningen så saknar transrasialitetsfältet både självidentifierade subjekt och även en egen social rörelse och egna företrädare och förespråkare.

Mot bakgrund av den kritik som Jay Prosser (1998) och andra forskare som själva är transpersoner har framfört gentemot en alltför utopiserande och i många fall också fetischiserande bild av och syn på dem vilken odlas inom vissa delar av genusoch queerforskningen, så innebär frånvaron av självidentifierade transrasiala subjekt ett etiskt problem. Min egen roll i detta är att jag själv är utlandsadopterad från Sydkorea och att jag i tidigare studier har undersökt icke-vita adopterades rasliga identifikationer och praktiker, och benämnt dem som transrasiala samtidigt som att jag är väl medveten om att utlandsadopterade själva inte betraktar eller benämner sig själva som transrasiala och inte heller kategoriserar adopte- 
rades olika organisationer, nätverk och rörelser sig själva som transrasiala (Hübinette 2006, 2007, 2008). Här finns med andra ord en risk att jag som forskare konstruerar och reproducerar en utopiserande och fetischiserande syn på en specifik demografisk grupp i de västerländska samhällena vilken redan är marginaliserad och osynliggjord i migrations- och diasporasammanhang även om jag själv tillhör gruppen i fråga.

Följande artikel består av en introduktion till fenomenet transrasialitet $\mathrm{i}$ form av en undersökning av dess praktik utifrån två olika empiriska exempel mot bakgrund av följande frågeställningar: Är det möjligt att överskrida ras på ett liknande sätt som det går att överskrida kön? Hur ser den transrasiala erfarenheten ut och hur skiljer den sig från den transrasiala fantasin? Vem eller vilka är transrasiala, och är det samma sak att transrasialisera från icke-vit till vit som från vit till icke-vit mot bakgrund av olika maktpositioner och handlingsutrymmen?

\section{DEN TRANSRASIALA ERFARENHETEN}

De sfärer i samhället där transrasialitet och dess olika avledningar används rör enligt den kanadensiska feministiska filosofen Cressida J. Heyes (2006) för det första dels det juridiska området i de europeiska bosättarkolonierna i Nord- och Sydamerika där ras är en officiell kategori i den postkoloniala staten och används i folkbokförings- och folkräkningssammanhang liksom i rättsliga kontexter. Här handlar det om enskilda individer som ibland helt enkelt byter ras i statistikens och juridikens värld, det vill säga de rastransformerar eller transrasialiserar, antingen för att de kan passera kroppsligt åt det ena eller det andra hållet eller för att de kan påvisa en viss genetisk härkomst. Det kan också handla om grupper i samhället som omklassificeras från en raskategori till en annan. Ett andra område rör enligt Heyes frågan om och erfarenheten av att kunna passera, ofta från icke-vit till vit och oftast för individer och grupper som är blandade, det vill säga de som har en vit och en ickevit förälder. Särkilt i USA har passing-fenomenet kommit att utvecklas till en egen genre inom kulturforskningen (se till exempel Ahmed 1999; Butler 1993: 167-185; Gaines 2005; Ginsberg 1996; Rottenberg 2003).

Det tredje exemplet enligt Heyes utmärkta genomgång av att överskrida ras, rör möjligheterna att kunna transrasialisera via kosmetik och kirurgi samt med hjälp av kläder och andra utseendemarkörer. Till denna uppräkning skulle jag vilja tillägga den anglo-amerikanska adoptionsforskningens användande av begreppet tranrasial adoption för den specifika inhemska nationella adoptionen av icke-vita minoritetsoch migrantbarn till vita adoptanter inom de västerländska nationalstaterna. Denna form av adoption har ända sedan dess uppkomst i kölvattnet av 68-rörelsen betraktats som kontroversiell, och rör bland andra svarta, latinamerikanska och asiatiska barn och urfolksbarn i USA, Storbritannien, Australien och Nya Zeeland (Gaber \& Aldridge 1994; Kirton 2000). Även om det etablerade uttrycket transrasial adoption just använder termen transrasial, så innebär inte detta mer än att barn förflyttas över rasgränserna, vilket i praktiken i de allra flesta fall innebär från icke-vita familjer och minoriteter till vita familjer och det vita majoritetssamhället.

Att tala om en transrasial erfarenhet, identifikation eller position är inte något som förekommer inom vare sig inom det kulturvetenskapliga fältet eller inom adoptionsforskningen. Jag menar dock att det i relation till icke-vita adopterade, och främst utlandsadopterade, går att tala om både en transrasial erfarenhet och en transrasial subjektsposition. Detta är vad jag har kommit fram till i min egen forskning som dels bygger på fenomenologiskt inspirerade närläsningar av icke-vita utlandsadopterades självbiografiska texter utgivna i olika västländer och dels bygger på djupintervjuer med icke-vita utlandsadopterade i Sverige (Hü- 
binette 2006, 2007; Hübinette \& Tigervall 2008, 2009). I de publicerade livsberättelserna hittas citat som dessa:

Plötsligt en dag var det en indier som tittade på mig i spegeln (von Melen 1998: 125).

Jag har aldrig identifierat mig med andra asiater. Kommer ihåg att Michael Chang vann French Open 1989 och alla mina sparringpartner i tennisklubben klappade mig på axeln och trodde att det måste kännas som en jättekul fjäder i hatten för en asiat som jag, som dessutom själv höll på med tennis. Faktum är att det bara kändes helt fel. Det var inte jag. Jag var Stefan Edberg. Jag hade inget gemensamt med Chang, jag var uppfostrad till skandinav. I min mentala spegelbild har jag alltid sett en ung muskulös blond kille med blåa ögon (Uppsala Publishing House 2003: 35).

Both my Danish and my American family are white, all my friends here in Denmark are white ... my husband is white ... and my two sons are often mistaken for being white. So whether I like it or not-and I actually don't-I've developed a white identity. When I look in the mirror I'm actually surprised to see an Asian woman and I honestly don't know how to feel about the woman I see. I actually expect to see a white woman with rosy skin, blond hair and blue eyes (Danish Asian 2001).

Även inom den kvantitativa adoptionsforskningen har denna transrasiala identifikation hos icke-vita utlandsadopterade konstaterats i form av självsvarsformulär där adopterade fătt självidentifiera sig antingen med hjälp av att peka på olika rasliga idealtypsdockor eller genom att kryssa i olika rasliga kategoriboxar, och där majoriteten identifierar sig som vita (Lee 2003). Det är viktigt att påpeka och komma ihåg att denna transrasiala identifikation inte bara handlar om att vilja bli vit som nog är fallet bland det stora flertalet icke-vita som lever per- manent i Väst, utan om att på en psykisk nivå uppleva sig inneha och bebo en vit kropp trots ett icke-vitt fysiskt yttre.

Den transrasiala subjektspositionen som de adopterade uppvisar handlar om det enkla demografiska faktum att det absoluta flertalet av de icke-vita adopterade, vare sig de härrör från Colombia, Haiti, Etiopien, Indien, Korea, Vietnam eller Kina, växer upp bland och fortsätter att i de allra flesta fall även som vuxna bo och leva bland vita, ofta som den enda icke-vita personen i sin närmaste omgivning. Utifrån deras uppväxt och vuxenliv i vita segregerade medel- och överklassmiljöer kan de adopterade sägas ha blivit subjektiverade som vita, och de kan också sägas iscensätta vithet performativt genom att tala ett västerländskt språk flytande och perfekt, genom att inneha västerländska och kristna namn och genom att klä sig och äta västerländskt. Samtidigt innebär denna transrasiala erfarenhet mycket smärta och lidande, för problemet är också att de inte alltid uppfattas som svenskar, danskar, nya zeeländare, belgare, islänningar, tyskar eller kanadensare av den vita majoritetsbefolkningen, det vill säga deras kroppar blir rasifierade och sammanlänkade med en upplevd brist, en annorlundahet och en icke-västerländskhet som länkar dem till den icke-västerländska världen och till icke-vita minoriteter.

Simon: För mina föräldrar förväntades jag vara som vilken svensk som helst, för de vill att det ska se normalt ut. Så det var väldigt sent som jag aktivt kom att tänka på det, det var först i gymnasieåldern. Samtidigt är det en identitet som de har byggt upp, och som resten av samhället förvägrar mig.

Tobias: Så fram till dess så gick du med andra ord runt och tänkte att du var vit?

Simon: Jaa, jaa, fast jag vet att den identiteten blev ifrågasatt hela tiden, och att jag mådde dåligt av det, men jag kunde inte sätta fingret på det, för det var en sådan blind fläck. Det var något man inte talade om, utan föräldrarna pekade på likhet. De tyckte, du har ju svart 
hår precis som jag, för min mamma råkar ha mörkt hår. Och mormor sade, men du ser ju mer svensk ut än de flesta adopterade (författarens intervju med Simon, adopterad från Korea).

Den transrasiala vithet som de adopterade identifierar sig med och iscensätter och lever med varje dag ifrågasätts med andra ord av en vit omgivning som uppfattar att de adopterade beter sig "fel" och "tvärtom", och vilket också är en erfarenhet som kan hittas i en del texter skrivna av transpersoner. Den hegemoniska färgblindhetsdiskurs som råder $\mathrm{i}$ den senmoderna västerländska kulturen och som tabuiserar allt tal om ras och i det närmaste förbjuder de adopterade att tala om sina icke-vita kroppar, skapar i kombination med vardagsrasistiska praktiker enligt min tolkning av texterna och intervjuerna en ifrågasatt och instabil vit transrasial subjektsposition som också producerar mycket psykiskt våld och i vissa fall även fysiskt våld. Ny kvantitativ adoptionsforskning i Sverige har nämligen indikerat att liksom bland transpersoner är psykisk ohälsa och social marginalisering alltför vanligt förekommande enligt populationsbaserade registerstudier (Carlberg \& Nordin Jareno 2007; Hjern \& Allebeck 2002; Hjern, Lindblad \& Vinnerljung 2002; Hjern, Vinnerljung \& Lindblad 2004).

Vuxna icke-vita utlandsadopterade mår sämre än både den vita majoritetsbefolkningen och de icke-adopterade icke-vita minoritetsgrupperna i Sverige trots en uppväxt i högutbildade och välbärgade adoptivfamiljer (ibid.) Detta gäller bland annat sjukskrivning, förtidspensionering och bidragsberoende, liksom psykiska sjukdomar, olika former av missbruk, kriminalitet och institutionsplaceringar samt suicidförsök. Vad gäller genomförd suicid så uppvisar gruppen icke-vita adopterade en femfaldig överrepresentation jämfört med den vita majoritetsbefolkningen, och faktum är att ingen annan demografisk subgrupp i det svenska samhället är så drabbad av suicid som just utlandsadopterade. Att bli transrasialiserad som icke-vit och att leva med den transrasiala erfarenheten spelar enligt min tolkning en avgörande roll för dessa resultat på samma sätt som att transpersoner kan mötas av ett ifrågasättande $\mathrm{i}$ vardagen och en dikotomiserande och homogeniserande beköning av deras kroppar som också kan resultera i social marginalisering och i värsta fall kan leda till suicid.

\section{TRANSRASIALA FANTASIER}

Det andra empiriska exemplet på transrasialitet i praktiken rör det omvända, det vill säga när vita transrasialiseras och blir ickevita. Detta ämne går ofta under beteckningen going native men som jag menar inte i egentlig mening kan jämföras med en transrasial erfarenhet utan snarare mer handlar om en transrasial fantasi om att som vit för en stund och temporärt vilja vara och bli den Andre. Denna transgression och transformation från vit till icke-vit kan på ett performativt plan sägas äga rum när vita lär sig icke-europeiska folks språk, inspireras av deras mathållning och klädskick och seder och bruk och intresserar sig för icke-kristna traditioner och religioner, något som har en lång tradition med namn som Lawrence av Arabien, Lafcadio Hearn, Pierre Loti, Mary Kingsley, Isabelle Eberhardt samt konstnärer som Paul Gauguin och Frida Kahlo, och av vilka många intressant nog var icke-heterosexuella (Price 1989; Torgovnick 1990). De transrasiala fantasierna och den vita transrasialiteten går att spåra tillbaks tills det koloniala projektets uppkomst. Transrasialitetstemat löper enligt min tolkning som en röd tråd genom den koloniala historien och kan sägas hemsöka även det samtida postkoloniala tillståndet. För att förstå detta är det nödvändigt att gå tillbaka till det första mötet mellan européerna och den övriga världen.

Den kanadensiske litteratur- och queerforskaren Terry Goldie hävdar att bilden av 
den infödde “vilden” i kanadensisk, australiensisk och nyzeeländsk litteratur som pendlar mellan alltifrån ett abjektivt äckel och en vilja att utrota denne till ett erotiskt begär efter att få ingå i relation med och till och med få barn med denna egentligen avspeglar och handlar om den europeiske kolonisatörens mer eller mindre permanenta anknytningsproblem till världen utanför Europa och dilemmat att aldrig helt kunna känna sig hemma bland icke-vita, och hans därpå följande ständiga behov av och begär efter att vilja bli den Andre vilket leder till ett slags ambivalent pendlande mellan ytterligheter där icke-vita ibland demoniseras och ibland romantiseras. En historisk genre som både avspeglar denna rädsla och fascination för att transrasialisera och att bli den Andre är de så kallade white slavery- och white captivity-berättelserna som skrevs och lästes i kolonierna och i Europa från 1500till 1800-talen (Darian-Smith, Poignant \& Schaffer 1992; Faery 1999; Jerng 2010). White slavery-berättelsen handlade om en vit person som varit slav hos ett icke-vitt folk, och denna typ av berättelse kunde ibland vara självbiografisk medan den ibland var fiktiv.

White captivity-temat som den engelska historiken Linda Colley (2002) har studerat handlar om alla de soldater, missionärer, resenärer, nybyggare, kolonisatörer och bosättare vilka under århundradenas lopp tillfångatogs av koloniernas infödda och som återvände till “civilisationen” och författade skrifter om sina upplevelser av att ha adopterats av och växt upp bland olika icke-vita folkslag. Denna genre rörde naturligtvis inte bara Brittiska imperiet, även om det engelskspråkiga materialet är kanske som mest rikhaltigt att döma av de otaliga titlar som finns om särskilt alla vita nybyggarbarn som växte upp och levde bland indianer, afrikaner och asiater som transrasialiserade vita såsom Mary Rowlandson The narrative of the captivity and restoration of Mary Rowlandson (1682), James Fenimore Coopers klassiker Den siste mobikanen (1826), The- resa Gowanlocks och Theresa Delaneys Two months in the camp of Big Bear (1885) och Rudyard Kiplings roman Kim (1901). Den svenska historikern Gunlög Fur (2006) har exempelvis uppmärksammat ett antal svenska white captivity-liknande exempel i Nya Sverige och Sameland.

Under 1960- och 70-talens avkolonialisering och i samband med den Tredje världen-inspirerade vänstervågen och $\mathrm{i}$ det samtida postkoloniala tillståndet har begäret efter att transrasialisera kommit att anta antirasistiska former. Den amerikanske författaren Jack Kerouac satte ord på denna längtan efter att vilja bli icke-vit i den berömda passagen i På drift (1957): “I wished I was a Negro, a Mexican, or even a Jap, anything but a white man disillusioned by the best in his own 'white' world." Andra exempel som uttryckt denna vilja att få leva med och bli den Andre är Carlos Castañedas, Marlo Morgans och Olga Kharitidis olika new age-klassiker om sina påstådda möten och relationer med indianer, aboriginer och sibirier, filmer som Karate Kid (1984), Den siste samurajen (2003) och Avatar (2009) och teveserier som BBCs Tribal Wives (2008) och SVTs Den stora resan (2009). Detta postkoloniala begär efter att som vit transrasialisera hittas också i dagens uppsjö av olika typer av så kallade whigger- och otaku-subkulturer liksom i alla de new age-rörelser som anammar olika former av så kallade "orientaliska" kvasireligiösa element.

Viljan att överskrida ras och att temporärt bli den Andre gör sig än mer märkbar inom den så kallade racial transformationgenren som inbegriper sådana titlar och exempel som den vite amerikanske journalisten John Howard Griffin i boken Black like me (1961) och den vite tyske journalisten Günter Wallraff i boken Ganz unten (1985) och i filmen Schwartz auf weiss (2009). Båda dessa har sminkat sig och klätt ut sig för att i antirasistiskt syfte kunna passera som svarta amerikaner, turkar och somalier. Ett annat exempel är den brittiske 
komikern Sacha Baron Cohens alla olika transrasiala förvandlingsnummer. Att spela en icke-vit karaktär har en lång historia inom scenkonsten och filmbranschen i en tid när icke-vita skådespelare inte tilläts uppträda eller inte fanns tillgängliga (Gubar 1997). Alla dessa exempel pekar också på den än så länge medicinska omöjligheten att byta ras till skillnad från att byta kön, även om fantasin om att detta är möjligt hålls vid liv som exempelvis $\mathrm{i}$ en episod $\mathrm{i}$ den amerikanska animerade teveserien South Park när en vit pojke genomgår ett kirurgiskt rasbyte för att bli svart.

\section{TransRasialiteT SOM POTENTIAL}

För att avsluta denna artikel om transrasialitetsbegreppet exemplifierat genom transrasiala erfarenheter och fantasier så vill jag återknyta till de eventuella likheter och skillnader som kan finnas mellan transrasialitet och transkönadhet. Med transrasialitet har jag i artikeln dels syftat på icke-vita adopterades identifikationer med vithet vilka hos dessa är insocialiserade och därmed ofta också omedvetna och ofrivilliga, och dels på vissa vita personers medvetna och frivilliga praktiker som syftar till att byta ras och bli icke-vita. Att beteckna både icke-vita utlandsadopterade liksom vita going nativepraktiker som transrasiala som jag har valt att göra i denna artikel är därför inte oproblematiskt, och en definition på transrasialitetsbegreppet inbegriper därmed både omedvetna och medvetna identifikationer liksom både ofrivilliga och frivilliga praktiker vilka leder till att en icke-vit eller en vit person transrasialiseras. Att överskrida ras är med andra ord för vissa marginaliserade grupper som saknar ett större handlingsutrymme inte en frivillig handling medan det för andra som tillhör normen och innehar både ett stort handlingsutrymme och maktpositioner är högst frivilligt och till och med njutbart.

För att återknyta till Heyes (2006) så argumenterar hon för att även om ras och kön båda är förkroppsligade kategorier, så bär ras på en historia av kolonialism och rasism som essentialiserar på ett annat sätt än kön. Heyes exemplifierar sitt argument med Michael Jackson som trots sina försök att bli vit ändå förväntades iscensätta svarthet. Med andra ord bär raskategorin på en stark biologiserings- och kulturaliseringstendens som försvårar och förhindrar rasöverskridande praktiker. En parallell vad gäller likheter mellan den transrasiala och den transkönade erfarenheten är dock en antingen-eller besatt omvärld som har svårt att acceptera kroppar och subjekt som iscensätter och identifierar sig "tvärtom", och vilka därför riskerar att disciplineras och isoleras liksom att utveckla psykisk ohälsa och i värsta fall straffas med biologisk död i form av transfobiskt våld eller självmord. Ännu en likhet gäller den utopiserande attityd som finns inom forskningen gentemot dessa båda grupper, där icke-vita adopterade ibland konceptualiseras som postrasiala nomader och kosmopoliter.

Det är vidare intressant att notera att både när ras och kön överskrids så finns det en tendens att uppvärdera, privilegiera och ibland även belöna de exempel när den överordnade blir den underordnade, det vill säga när vit blir till icke-vit och när man blir till kvinna. Vad gäller transrasialitet så är det till och med så att den koloniala historiens tidigare stigmatiserade transrasiala vita i white slavery- och white captivitygenrerna idag romantiseras och sentimentaliseras och i det närmaste hyllas som antirasister med spelfilmen Avatar (2009) som ett tydligt exempel på detta. Samtidigt finns det också “omvända" exempel i olika kulturproduktioner på när icke-vita transrasialiseras till vita förutom exemplet adopterade. Jag syftar här bland annat på den svarte amerikanske skådespelaren Eddy Murphy som spelar vit i sketchen White like me (1984), den amerikanska reality-teveserien Black. White (2006) där en vit och en svart familj byter liv med varandra och Babak Najafis svenska kortfilm Elixir (2003) som 
bygger på en novell av Alejandro Leiva Wenger där en grupp icke-vita ungdomar i en svensk förort förvandlas till vita överklassungdomar. Att överskrida ras från ickevit till vit blir inte lika uppmärksammat som det motsatta och ej heller lika hyllat, och de som gör det ses kanske snarare som lustiga och humoristiska eller till och med som monstruösa rasöverskridande freaks i likhet med fallet Michael Jackson och nog också vad gäller utlandsadopterade. För mig är det denna typ av transrasialitet, det vill säga från icke-vit till vit, som bär på en transformativ potential inför framtiden i en senmodern västerländsk värld där ras betyder alltmer för att särskilja och urskilja överordnade från underordnade och i slutänden vem som förtjänar att leva och vem som inte gör det.

\section{Note}

1. Tendensen att ersätta ras med etnicitet är särskilt påtaglig i nordiska forskningssammanhang och går tillbaka på en färgblindhet som har tabubelagt allt tal om ras och vithet i en samtida nordisk kontext (Hübinette \& Tigervall 2009).

\section{LITTERATUR}

- Ahmed, Sarah (1999): "She'll wake up one of these days and find she's turned into a nigger!", i: Theory, Culture \& Society 1999/2.

- Ahmed, Sarah (2006): Queer Phenomenology. Orientations, Objects, Others. Duke University Press, Durham.

- Alcoff, Linda Martín (2005): Visible Identities. Race, Gender and the Self. Oxford University Press, London.

- Butler, Judith (1993): Bodies that Matter: On the Discursive Limits of "Sex". Routledge, New York.

- Butler, Judith (2004): Undoing Gender. Routledge, New York.

- Carlberg, Margareta och Karin Nordin Jareno (red) (2007): Internationellt adopterade i Sverige. Vad säger forskningen?. Gothia förlag, Stockholm. - Cheng, Anne Anlin (2001): The Melancholy of Race. Psychoanalysis, Assimilation and Hidden Grief. Oxford University Press, Oxford.
- Colley, Linda (2002): Captives. The Story of Britain's Pursuit of Empire and How Its Soldiers and Civilians Were Held Captive by the Dream of Global Supremacy, 1600-1850. Pantheon Books, New York.

- Danish Asian: Adoptee's Struggle Between Finding Herself and Fitting in. Lokaliserad d. 25/8 2001 på http://www.goldsea.com/Air/True/ILF/adoptee.html

- Darian-Smith, Kate, Roslyn Poignant och Kay Schaffer (red) (1992): Captured Lives. Australian Captivity Narratives. University of London, London.

- Dyer, Richard (1997): White. Essays on Race and Culture. Routledge, London.

- Eng, David L. (2010): The Feeling of Kinship. Queer Liberalism and the Racialization of Intimacy. Duke University Press, Durham.

- Faery, Rebecka Blevins (1999): Cartographies of Desire. Captivity, Race, and Sex in the Shaping of an American Nation. University of Oklahoma Press, Norman.

- Frankenberg, Ruth (1993): White Women, Race Matters. The Social Construction of Whiteness. University of Minnesota Press, Minneapolis.

. Fur, Gunlög (2006): Colonialism in the Margins. Cultural Encounters in New Sweden and Lapland. Brill, Leiden.

- Gaber, Ivor och Jane Aldridge (red) (1994): Culture, Identity and Transracial Adoption. Free Association Books, London.

- Gaines, Jane (2005): In-and-Out-of-Race: The Story of Noble Johnson, i: Women and Performance: A Journal of Feminist Theory 2005/1.

- Ginsberg, Elaine K. (red) (1996): Passing and the Fictions of Identity. Duke University Press, Durham.

- Goldie, Terry (1989): Fear and Temptation. The Image of the Indigene in Canadian, Australian and New Zealand Literatures. McGill-Queen's University Press, Montreal.

- Grosz, Elizabeth (1994): Volatile Bodies. Toward a Corporeal Feminism. Indiana University Press, Bloomington.

- Gubar, Susan (1997): Racechanges. White Skin, Black Face in American Culture. Oxford University Press, New York.

- Hawkins, Stephanie L. (2004): Building the "Blue" Race: Miscegenation, Mysticism, and the language of Cognitive Evolution in Jean Toomer's "The Blue Meridian", i: Texas Studies in Literature and Language 2004/2.

- Heyes, Cressida J. (2006): Changing Race, Changing Sex: The Ethics of Self-Transformation, i: Journal of Social Philosophy 2006/2. - Hjern, Anders och Peter Allebeck (2002): Suici- 
de in First- and Second-Generation Immigrants in Sweden. A Comparative Study, i: Social Psychiatry and Psychiatric Epidemiology 2002/9.

- Hjern, Anders, Frank Lindblad och Bo Vinnerljung (2002): Suicide, Psychiatric Illness, and Social Maladjustment in Intercountry Adoptees in Sweden: A Cohort Study, i: The Lancet 2002/360. - Hjern, Anders, Bo Vinnerljung och Frank Lindblad (2004): Avoidable Mortality among Child Welfare Recipients and Intercountry Adoptees: A National Cohort Study, i: Journal of Epidemiology and Community Health 2004/5.

. Hübinette, Tobias (2006): Att leva i den andres kropp: Om rasifierade erfarenheter och transrasiala identifikationer i utlandsadopterades självbiografier, i: Locus: Tidskrift för forskning om barn och ungdomar 2006/4.

- Hübinette, Tobias (2007): Disembedded and Free-Floating Bodies Out-of-Place and Out-ofControl: Examining the Borderline Existence of Adopted Koreans", i: Adoption and Culture $2007 / 1$.

. Hübinette, Tobias och Carina Tigervall (2008): Erfarenheter av rasifiering hos adopterade och adoptivföräldrar: Om betydelsen av ett icke-vitt utseende i den svenska vardagen, i: Socialvetenskaplig Tidskrift 2008/3-4.

- Hübinette, Tobias och Carina Tigervall (2009): To Be Non-White in a Colour-Blind Society: Conversations with Adoptees and Adoptive Parents in Sweden on Everyday Racism, i: Journal of Intercultural Studies 2009/4.

- Jerng, Mark C. (2010): Claiming Others: Transracial Adoption and National Belonging. University of Minnesota Press, Minneapolis.

- Kirton, Derek (2000): “Race”, Ethnicity and Adoption, Open University Press, Buckingham.

- von Melen, Anna (1998): Samtal med vuxna adopterade. Rabén Prisma, Stockholm.

- Lee, Richard M. (2003): The Transracial Adoption Paradox: History, Research, and Counseling Implications of Cultural Socialization, i: The Counseling Psychologist 2003/6.

- Myong Petersen, Lene (2009): Adopteret-Fortellinger om transnational og racialiseret tilblivelse. Aarhus Universitet, Institut for Læring, DPU. - Newlyn, Andrea K. (2002): "Reassignment": The Politics of Transracial Crossing in Sinclair Lewis's Kingsblood Royal, i: Modern Fiction Studies $2002 / 4$.
. Omi, Michael och Howard Winant (1986): Racial Formation in the United States: From the 1960s to the 1980s. Routledge \& Kegan Paul, New York. - Price, Sally (1989): Primitive Art in Civilized Places. University of Chicago Press, Chicago. - Prosser, Jay (1998): Second Skins. The Body Narratives of Transsexuality. Columbia University Press, New York.

- Rottenberg, Catherine (2003): Passing: Race, Identification, and Desire, i: Criticism 2003/4. - Torgovnick, Marianna (1990): Gone Native. Savage Intellects, Modern Lives. University of Chicago Press, Chicago.

- Uppsala Publishing House (2003): Svartskallar. Så funkar vi. Uppsala Publishing House, Uppsala.

\section{SUMMARY}

To transcend race: An introduction to the concept of transraciality seen through transracial experiences and fantasies

This article introduces the concept of transraciality based on the following questions: Is it possible to transgress race in a similar way as it is possible to transgress sex? How does the transracial experience look like and how does it differ from a transracial fantasy? Who is transracial, and is it the same to transracialize from non-white to white as from white to non-white? The article takes up the experiences of non-white adoptees and their identifications of being white and of white people who want to become non-white both in a colonial and in a postcolonial setting, and argues that it is the non-white to white race transgression which has the potential to transform a dichotomous and hierarchical racial structure.

Tobias Hübinette

Mångkulturellt centrum och Södertörns högskola 